\title{
A High-Speed Photography Study of Cavitation in a Dynamically Loaded Journal Bearing
}

D.C. Sun

State University of New York at Binghamton

Binghamton, New York

and

D.E. Brewe

Propulsion Directorate

U.S. Army Aviation Research and Technology Activity-AVSCOM Lewis Research Center

Cleveland, Ohio

Prepared for the

Joint Tribology Conference

cosponsored by the ASME and STLE

Toronto, Canada, October 7-10, 1990 


\title{
A HIGH-SPEED PHOTOGRAPHY STUDY OF CAVITATION IN A DYNAMICALLY LOADED JOURNAL BEARING
}

\author{
D.C. Sun* \\ Department of Mechanical and Industrial Engineering \\ Thomas J. Watson School of Engineering, \\ Applied Science, and Technology \\ State University of New York at Binghamton \\ Binghamton, New York 13902-6000 \\ and \\ D.E. Brewe $\dagger$ \\ Propulsion Directorate \\ U.S. Army Aviation Research and Technology Activity - AVSCOM \\ Lewis Research Center \\ Cleveland, ohio 44135
}

\section{ABSTRACT}

The earlier study made by Jacobson and Hamrock on the cavitation of

liquid lubricant films in a dynamically loaded journal bearing was repeated with a quartz sleeve, which was more rigid than the Polymethylmethacrylate (PMMA) sleeve used previously. Various improvements of the test rig were made concomitantly so that the experimental errors could be better controlled and assessed. This paper describes the updated high-speed photography experiment and its results.

*Summer Faculty Fellow at NASA Lewis Research Center; member ASME. tMember ASME. 


\section{NOMENCLATURE}

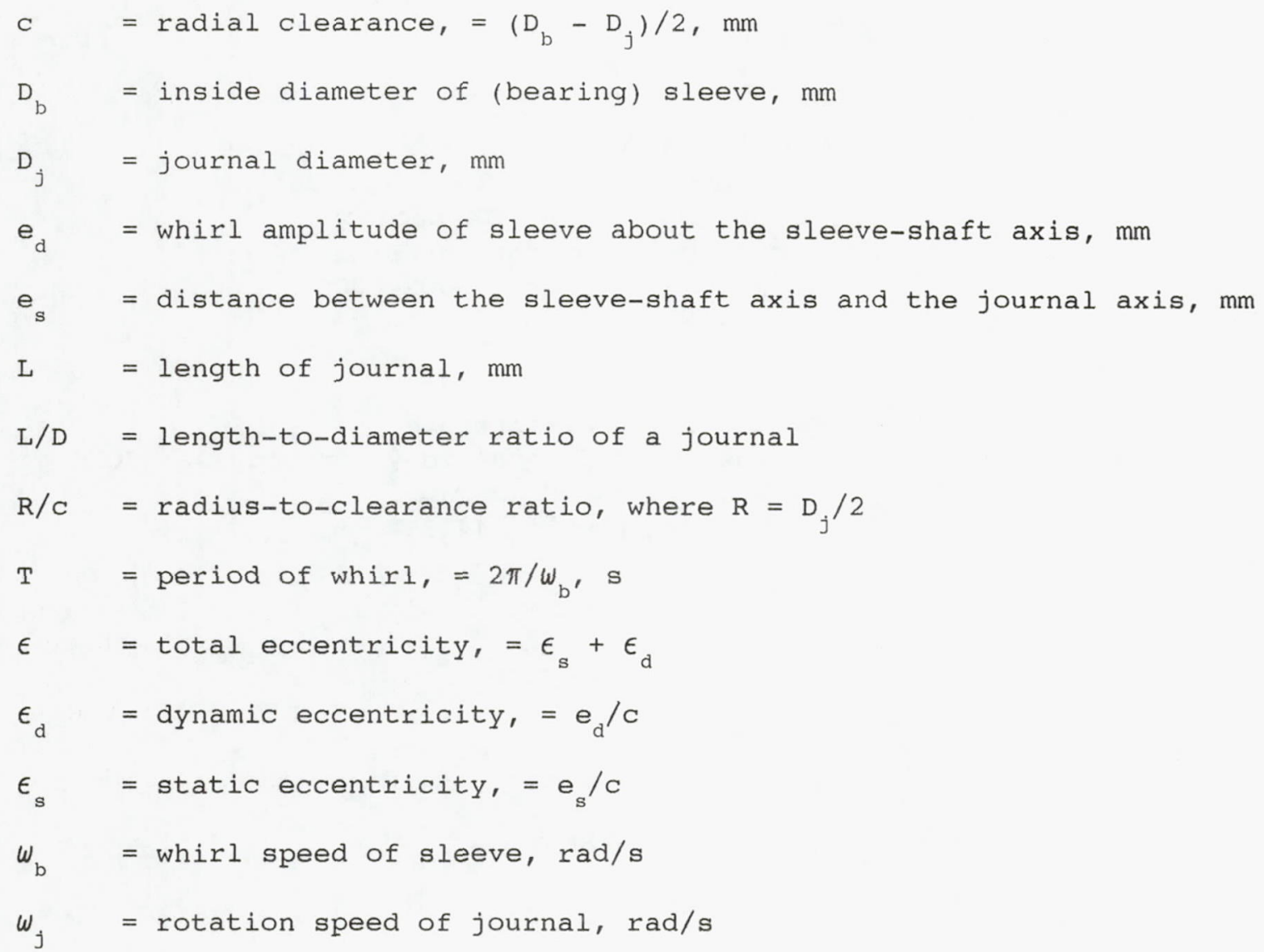

\section{INTRODUCTION}

Cavitation of the liquid lubricant film in a journal bearing affects bearing performance significantly. For stationary cavitation (resulting from steady bearing loads), the phenomenon and its consequence are reasonably well understood (Dowson and Taylor, 1974). For dynamic cavitation (resulting from unsteady bearing loads), even the basic aspects of the phenomenon are not clear. Unresolved questions include: What are the criteria for the onset of dynamic cavitation? What is the contents of a cavitation bubble? Can the 
cavitation bubble(s) be clearly separated from the full film region, or are they so numerous and thoroughly mingled with the liquid that the film can be, or should be, treated as a two-phase fluid? And, in the latter case, what are the physical properties of the two-phase fluid? These and other intriguing questions have motivated many studies.

White (1970) recorded in his dissertation the behavior of a squeeze film journal bearing. In the experimental setup the journal was non-rotating $\left(\omega_{j}=0.0 \mathrm{rad} / \mathrm{s}\right)$ and fixed; the sleeve was also non-rotating, but made to whirl about the sleeve-shaft axis, which was aligned with the journal axis. Thus, the case studied was one of "centered whirl" $\left(\epsilon_{s}=0\right)$. He found that the film force followed the prediction of the conventional lubrication analysis with an incompressible fluid up to $\epsilon_{d}=0.2$; beyond that the film force fell below the predicted value. This feature was observed in the entire range of the investigated whirl speeds $\left(w_{b}=31.42\right.$ to $\left.314.26 \mathrm{rad} / \mathrm{s}\right)$. He also observed, through a clear perspex sleeve, that cavitation bubbles in the film did not collapse in the high pressure region at large $\epsilon_{\mathrm{d}}$ values. He then suggested that the persistence of bubbles in the high pressure region was responsible for the reduced level of the film force. Hibner and Bansal (1979) measured the pressure distribution in a squeeze film bearing, also operated in the centered whirl mode, and found the measured results in discord with the prediction of the conventional incompressible lubrication theory. They reasoned that the disagreement was caused by the compressibility effect of 
gaseous cavitation ${ }^{1}$. Hence, they proposed a variable-density two-phase fluid model that could better correlate the measured data. Feng and Hahn (1987) actually carried out the computation using a two-phase fluid model. They found, however, that both the two-phase fluid model and the conventional incompressible lubrication theory (with the cavitation pressure set at absolute zero) agreed with the measurement made on their own squeeze film bearing rig. Walton et al (1987) conducted a visual study of the cavitation in a squeeze film bearing, operated in the centered whirl mode, using high speed photography and stroboscopic video recording. They reported that the incompressible lubrication analysis they used did not adequately account for the observed cavitation pattern; but they did not report any evidence of the formation of a two-phase fluid. Recently, Zeidan and Vance (1989) conducted both pressure measurement and visual study of the cavitation in a centered whirl squeeze film bearing. Based on their findings, they proposed that three operating regimes existed in the bearing: At low whirl speeds the film was uncavitated; at high speeds ( $>157.08 \mathrm{rad} / \mathrm{s})$ a two-phase fluid was formed; and at intermediate speeds some intermediate situation occurred. They observed the occurrence of vapor cavitation also, and attributed it to the presence of end seals, which hindered the process of drawing ambient air into the bearing clearance during the operation of the squeeze film bearing.

The study of dynamic cavitation at NASA Lewis Research Center began in the early eighties. Jacobson and Hamrock (1983a,b) built a dynamically loaded

1 Over the years the following terminology has emerged in the lubrication circle: If the cavitation bubbles in the film survive the high pressure portion of the pressure cycles, the cavitation is called gaseous;otherwise it is called vapor cavitation. 
journal bearing rig for visual studies. The transparent sleeve (made of polymethylmethacrylate, or PMMA) was non-rotating, but could be made to whirl about the sleeve-shaft axis at prescribed $\epsilon_{\mathrm{d}}$ values. The journal could rotate, and its axis could be shifted away from the sleeve-shaft axis to produce prescribed $\epsilon_{\mathrm{s}}$ values. Hence, "non-centered whirl" could be studied on this rig. Using high speed photography they were able to record the development and disappearance of cavitation, and determine its duration. The cavitation was found to be in the form of one bubble, even though the bubble sometimes displayed inner structures. They did not observe the formation of a two-phase fluid in any of their studied cases. Subsequently, Brewe (1986) computed the film flow solution considering dynamic cavitation, and found reasonably good agreement between the computed cavitation duration and the one measured by Jacobson and Hamrock. The theoretical model used was the classical single phase fluid, but the determination of the motion of the cavitation bubble was made easier with the use of a clever algorithm (Elrod, 1981). The good agreement seemed to imply that the single phase fluid was appropriate to model dynamic cavitation.

The present work is a continuation of Jacobson and Hamrock's experiment. The PMMA sleeve used in their studies was suspected to suffer from elastic deformation during the pressure cycles. Hence, the experiment was repeated with a newly acquired quartz sleeve. Concomitantly, several improvements of the test rig were made so that the experimental errors could be better controlled and assessed. This paper describes the improved test rig and the updated experimental results. 


\section{APPARATUS}

\section{General Layout}

The journal bearing rig consisted mainly of a journal and a sleeve (Figs. 1). The sleeve support structure (1) was fixed to a steel base (2); the journal support structure (3) was anchored to a cross slide (4), which was fixed to the base. The base was clamped down on a sturdy, flat machine table (5) whose level was adjustable.

The shaft holding the sleeve was supported on two precision ball bearings. One end of the shaft was connected to the sleeve mounting plate 6 through a dynamic eccentricity device (7); the other end of the shaft was connected through a flexible coupling to a variable-speed dc motor (with a maximum speed of about $261.80 \mathrm{rad} / \mathrm{s}$ ) which was bolted directly to the machine table. The two ball bearings were preloaded to reduce the shaft play to within $12.5 \mu \mathrm{m}$. Further preloading of the bearings made it difficult to turn the shaft.

The shaft holding the journal was supported on two precision ball bearings, preloaded in the same manner, and connected to a motor of identical make.

The sleeve-shaft axis and the journal axis were located in a plane parallel to the base. However, during the test it was necessary to clamp down the cross slide to suppress the vibration of the journal support structure. 
This operation lowered the journal axis, and shims were used to compensate for it. The error in leveling the two axes was within $12.5 \mu \mathrm{m}$.

The journal axis could be moved horizontally away from the sleeve-shaft axis by using the cross slide. To control the offset distance and to ensure that the two axes remained parallel, two dial indicators were used simultaneously to monitor the displacement of the journal support structure.

\section{The Journals}

Four steel journals were used in the study. Three were $84.0 \mathrm{~mm}$ in diameter and had L/D values of $0.25,0.5$ and 1.0 respectively. Another was $84.58 \mathrm{~mm}$ in diameter and had a $\mathrm{L} / \mathrm{D}$ value of 0.25 . The diametrical tolerance was $10 \mu \mathrm{m}$. The journal surfaces were ground within $0.2 \mu \mathrm{m}$ roughness (arithmetic average). Initial filming revealed that the glare of the journal surface made it difficult to resolve the cavitation boundary. Hence, the journal surfaces were treated chemically to produce a gun metal finish.

\section{The sleeve}

A precision-bore quartz sleeve was acquired from a German company. The inside diameter of the sleeve was $85.0 \mathrm{~mm}$, and it was $5.5 \mathrm{~mm}$ thick and 100.0 $\mathrm{mm}$ long. The variation in both its ID and OD was within $25 \mu \mathrm{m}$. The sleeve was inserted in a groove made in the face of the mounting plate (6) and glued by epoxy. Special care was exercised in the mounting procedure so that the sleeve was truly perpendicular to the plate. The mounting was so rigid that 
one could not move the two pieces relative to one another without breaking the sleeve.

The dynamic eccentricity device was similar to that previously reported (Jacobson and Hamrock, 1983a, Fig. 3), except that the inner piece was a new, modified version. The inner piece was pressed on the shaft; the outer piece was attached to the mounting plate via a precision ball bearing. The internal clearance of the ball bearing was removed by interference fit between the outer ring and the circular seat made in the back of the mounting plate. The relative angular position of the two pieces could be fixed with set screws to generate any desired $e_{d}$ value between 0 and $0.5 \mathrm{~mm}$.

It should be mentioned that the static eccentricity was generated by always moving the journal axis toward the side where the movie camera was situated. The camera was set at the same level as the journal bearing. Hence, the minimum-minimum clearance always appeared in the middle of the camera's view (covering nearly 180 degrees of the bearing circumference).

The mechanism (8) that kept the axis of the whirling sleeve parallel to the sleeve-shaft axis was explained previously (Jacobson and Hamrock, 1983a, Fig. 7). The screws that fixed the spring steel plates of the mechanism to the sleeve mounting plate were tightened after the dynamic eccentricity device was carefully aligned. Once tightened, these screws could maintain the alignment for an extended period of running. 
A thin rubber boot (9) was used to seal the gap between the sleeve and the journal support structure. Assisted by a wire clamp and vacuum grease, the seal was effective in preventing the lubricant fluid from leaking out of the space confined by the sleeve (hereafter to be referred to as the test chamber). However, the test chamber was not air tight because air could enter it via the two ball bearings situated at its ends.

\section{Lubricant Supply}

The lubricant used in the study was DEXRON II automatic transmission fluid. Its kinematic viscosity was determined to be 38.1 ct at $40^{\circ} \mathrm{C}$ and 6.86 ct at $100^{\circ} \mathrm{C}$; and its specific gravity to be 0.86 at $40^{\circ} \mathrm{C}$.

The fluid was fed by gravity to the test chamber from a reservoir (10) located about $0.45 \mathrm{~m}$ above. Hence, the experiment simulated the operation of a submerged bearing without feed grooves. The fluid entered the test chamber from one side through an opening drilled in the sleeve mounting plate near its bottom. Then the fluid left the test chamber from the other side via an outlet (equipped with a valve) (11) located at the top of the journal support structure. The outflowing fluid was filtered, collected, and returned to the reservoir.

The reservoir was a pressure vessel. Degassing of the fluid was performed by pumping air out of the reservoir and then leaving the fluid 
overnight in the partial vacuum condition at an absolute pressure of approximately 66.6 Pa. Aeration of the fluid was performed by drawing air into the reservoir, generating violent mixing between the air and the fluid. The degree of degassing and aeration was not determined, however.

The test was conducted in an ordinary laboratory environment. No special attempt was made to control the temperature of the fluid.

\section{Instrumentation}

The whirl speed of the sleeve was monitored by an electronic counter connected to a magnetic pickup which was actuated by a 60-tooth gear disk mounted on the shaft. The rotation speed of the journal was read with a stroboscope.

A capacitance type proximeter probe was placed behind the sleeve (i.e. on the opposite side of the camera) to monitor the displacement of the sleeve. The output signal of the probe passed through a differentiator and a zero counter, then triggered a light emitting diode (LED). The LED lit up as the sleeve was moving toward the camera; and turned off when the sleeve was moving away. The LED was included in the film to mark the time when the minimumminimum clearance occurred.

The photographic setup was as previously described (Jacobson and Hamrock, 1983a, Fig. 8). The camera speed was set at 2000 frames per second, and the shutter speed was $1 / 5000$ seconds. The filming of a run took about 
three seconds, only in the middle part of this duration did the camera attain its pre-set speed. The camera speed could be verified, however, by counting the number of frames for the completion of a revolution of the dynamic eccentricity device. Since the sleeve-shaft speed was monitored by an electronic counter, the counter reading and the film provided each other a mutual check.

Because of the darkened finish of the journal surface and the high camera speed, intensive lighting was needed for the photography to reveal the occurrence of cavitation. To alleviate the heating effect of the lamps, a cooling fan was installed and the duration of lamp use was minimized.

\section{TEST PROCEDURE}

The parameters that could be varied in the study were $R / C, L / D, \epsilon_{s^{\prime}} \epsilon_{d}$, $w_{j}, w_{b}$, and the condition of the fluid. Once a case was planned for photography, the following steps were carried out:

(1) Mount the required journal. Use a dial indicator to check its run-out.

(2) Rotate the dynamic eccentricity device to obtain $\epsilon_{\mathrm{d}}=0$. Use a dial indicator to double check this centered position of the sleeve.

(3) Use the cross slide to move the journal from one side of the sleeve to the other. Determine the total clearance and locate the position of $\epsilon_{\mathrm{s}}$ $=0$. Then move the journal to the position with the prescribed $\epsilon_{\mathrm{s}}$ value. 
(4) Rotate the dynamic eccentricity device to obtain the prescribed $\epsilon_{\mathrm{d}}$ value. Again use a dial indicator to double check this setup. Then fix the relative position of the dynamic eccentricity device by tightening the set screws.

(5) Use a big C-clamp to fix the position of the cross slide.

(6) Connect the motors; pre-set the assigned speeds $\omega_{j}$ and $\omega_{b}$; and install the proximeter probe and LED.

(7) Tighten the bellow seal and fill the test chamber with the prepared fluid. In the case of degassed fluid, the preparation was done overnight; in the case of aerated fluid, the mixing of the fluid with air was performed just before filling.

(8) Set up movie camera and lighting arrangement; turn on the cooling fan; then run the rig. Double check (and adjust) the value of $w_{j}$ with a stroboscope.

(9) Film the run.

(10) One roll of film was used to photograph two, or sometimes three, runs. The subsequent runs were either for different speed settings or for changing from the case of degassed fluid to that of aerated fluid.

\section{RESULTS AND DISCUSSION}

Eighty three runs were filmed, many of which were not usable either because of poor resolution due to inadequate lighting, or because of errors in the setup which were later discovered. The following paragraphs summarize the best information obtained. 


\section{Onset of Cavitation}

The occurrence of cavitation was crucially dependent on the bearing clearance. Persistent cavitation patterns were observed in the case of $\mathrm{R} / \mathrm{C}=$ 201.0 at whirl speeds as low as $31.42 \mathrm{rad} / \mathrm{s}$; but in the case of $\mathrm{R} / \mathrm{c}=84.0$, only a faint pattern was produced at a whirl speed as high as $92.68 \mathrm{rad} / \mathrm{s}$. The other parameter values in the two cases were the same: $\mathrm{L} / \mathrm{D}=0.25, \epsilon_{\mathrm{s}}=$ $0.4, \epsilon_{\mathrm{d}}=0.5, \omega_{j}=0.0 \mathrm{rad} / \mathrm{s}$. With a given bearing clearance, cavitation occurred only at high whirl speed and large eccentricity. The high eccentricity needed for the onset of cavitation should be qualified, however. The play of the sleeve and journal shafts could each be $12.5 \mu \mathrm{m}$. The errors were cumulative, resulting in an uncertainty in the eccentricity value of 0.05 for the small diameter journal, and 0.12 for the large diameter journal. In the following, only the cases where cavitation was found are discussed. These cases were all labelled with large eccentricity values. These values were read from the setup; their actual magnitudes would be smaller, within the above-mentioned margins of uncertainty.

\section{Centered versus Non-Centered Whirl}

The cavitation pattern was fundamentally different in these two types of whirl. For the centered whirl $\left(\epsilon_{\mathrm{s}}=0\right)$, as the low pressure wave revolved around the bearing circumference, it caused the lubricant film to locally cavitate. This gave rise to the appearance of a revolving bubble in synchronization with the whirling sleeve. For the non-centered whirl $\left(\epsilon_{\mathrm{s}} \neq\right.$ $0)$, the cavitation bubble emerged amidst the fluid film, grew to its peak 
size, then shrank and collapsed, leaving no residual bubbles in the aftermath. Figures 2 present several frames of photographs from the film, showing the series of stages that a typical cavitation bubble went through. In either type of whirl it was not possible to tell by visual study alone whether the contents of the void region was air, vapor, or a mixture of the two. Occasionally, one or two air bubbles were present in the test chamber due to imperfect venting. These bubbles would stay in the same circumferential position (when the journal was not in rotation), and would enter and leave the bearing clearance following the pressure cycles. It was evident that the behavior of the cavitation bubble was distinctly different from these entrained air bubbles.

\section{Effect of Whirl Speed and Amplitude}

As previously mentioned, high whirl speed and large eccentricity prompted the occurrence of cavitation. These conditions also caused the cavitation bubble to be large and its duration long. The effects are demonstrated by the photographs in Figs. 3. These (and subsequent) photographs were extracted from the films where the respective cavitation bubbles were at their peak sizes. The cavitation duration is expressed in terms of the whirl period (T), and is indicated in the figures. It should be mentioned that the sleeve whirled in the clockwise direction as viewed from the sleeve side; and in all the photographs presented in this paper, the sleeve was moving toward the camera. 


\section{Effect of Bearing Clearance}

A smaller bearing clearance would generate a larger cavitation bubble and a longer cavitation duration. This effect can be clearly seen by comparing Fig. 4(a) with Fig. 4(b). By changing the R/c value from 84.0 to 201.0, the cavitation duration increased by forty-three percent. For an higher whirl speed of $146.61 \mathrm{rad} / \mathrm{s}$, the corresponding increase in cavitation duration was less, i.e. twenty percent. (Compare Fig. 4(C) with Fig. 3(d).)

\section{Effect of Journal Rotation}

Figures 5 and 6 exhibit this effect. When the journal was rotating in the same direction as the sleeve was whirling, Figs. $5(b)$ and $6(b)$, the journal surface was moving upward and carried the cavitation bubble with it. This action prolonged the cavitation duration. The effect was so strong that, in the case of Fig. 6(b), the cavitation bubble survived through and beyond the view of the camera. As a result, its duration could not be determined. When the journal was rotating opposite to the direction of whirl, Figs. 5(C) and $6(c)$, the journal surface was moving downward, and its effect appeared to be retarding the motion of the cavitation bubble.

\section{Effect of Journal Length}

Figures 5 and 6 also demonstrate this effect. As shown, the cavitation bubble was larger, and its duration longer, in the case of a longer journal. But the trend did not carry to $L / D=1$. In this case, one end of the journal 
was too close to the journal support structure. As a result, air was drawn in through the ball bearing, and then it entered the bearing clearance in the form of bubbles. The photographs in Figs. 7 illustrate this effect. The operating parameters for Fig. 7 (a) correspond to those for Figs. 5 (a) and 6(a); likewise, Fig. 7 (b) corresponds to Fig. 4(a). From these photographs it can be seen that the entrained bubbles were leaning to the side of the journal support structure. (Notice also that the journal was partly covered by the bellow seal.) The bubbles did not cluster together to form a large cavitation region; nor did they exhibit a definitive duration of existence. In short, the presence of these entrained air bubbles suppressed the occurrence of the cavitation pattern previously discussed.

\section{Degassed versus Aerated Fluid}

Throughout the cases studied, no difference in the cavitation pattern between the degassed and the aerated fluid was observed. This could be the result of the degassing and aeration procedures. These operations were carried out in the reservoir. Then the fluid must pass through a tygon tubing to enter the (air filled) test chamber. The filling process took several minutes. It was possible that after the process the fluid lost its prepared condition. On the other hand, if the procedures are considered acceptable, then the implication of the observation would be that the persistence of air bubbles in the high pressure region, as reported in the literature, might be due to air entrained in the lubricant film, rather than due to the liberation of the dissolved air within the fluid. 
A set of conditions $\left(R / C=201.0, L / D=0.25, \epsilon_{s}=0.4, \epsilon_{d}=0.5, w_{j}=\right.$ $0.0 \mathrm{rad} / \mathrm{s}, \omega_{b}=104.72 \mathrm{rad} / \mathrm{s}$ ) was chosen for a continuous run to see if a long duration test would lead to the formation of a two-phase fluid in the lubricant film. It was found that the cavitation pattern, as previously described, remained unchanged after an hour. The test was then continued with lower whirl speeds, and persistent patterns were found down to $w_{\mathrm{b}}=31.42$ $\mathrm{rad} / \mathrm{s}$. Further lowering of the speed made the cavitation pattern an irregular occurrence.

The whirl speeds used were admittedly low in comparison with those found in the applications of squeeze film bearings. But they should be adequate to reveal the persistence of bubbles in the high pressure region, in view of the fact that white (1970) observed the same at speeds as low as $31.42 \mathrm{rad} / \mathrm{s}$. Thus, one might conclude that the formation of a two-phase fluid was not the result of the liberation of the dissolved air within the fluid.

\section{SUMMARY}

The earlier investigation by Jacobson and Hamrock using high-speed photography to study the cavitation in a journal bearing, under controlled orbital motion, was repeated on an improved rig. The following results were obtained: 
1. The basic findings of Jacobson and Hamrock were confirmed, viz. for the non-centered whirl, the cavitation bubble emerged amidst the fluid, grew in size, then shrank and collapsed.

2. For the centered whirl, as the low pressure wave revolved around the bearing circumference, it caused the lubricant film to locally cavitate, giving rise to the appearance of a revolving bubble in synchronization with the whirling sleeve. In both the centered and non-centered whirl cases, no air bubbles were found surviving the high pressure portion of the pressure cycles.

3. Small bearing clearance, high whirl speed, and large eccentricity prompted the occurrence of cavitation. These conditions also caused the cavitation bubble to be large and its duration long.

4. When the journal rotated in the same direction as the sleeve whirled, the journal surface carried the cavitation bubble with it and prolonged the cavitation duration. When the journal rotated in the opposite direction, the motion of the cavitation bubble was retarded, and its duration was also longer than when the journal was not in rotation.

5. The cavitation bubble was larger, and its duration longer, in the case of a longer journal. But the trend did not carry to $L / D=1$ in the present apparatus. In this case, air bubbles were drawn into the film from one end of the test chamber. The presence of these entrained air bubbles suppressed the occurrence of the one-region cavitation pattern.

6. Throughout the cases studied, no difference in the cavitation pattern between the degassed and the aerated fluid was observed. This and other observations obtained in the study seemed to indicate that the formation 


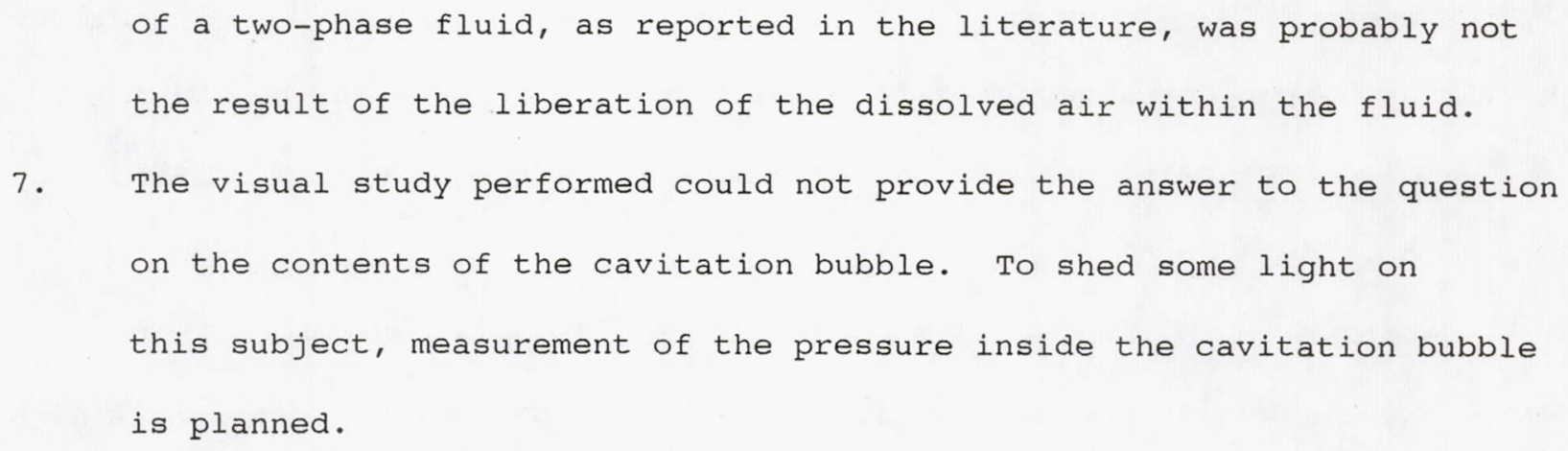

\section{ACKNOWLEDGMENTS}

The authors would like to thank Mr. Eugene Farkus for his painstaking assistance in every detailed aspect of this work, and Mr. David Clinton for carrying out the laborious task of photographing the cavitation.

\section{REFERENCES}

Brewe, D. E., 1986, "Theoretical Modeling of the Vapor Cavitation in Dynamically Loaded Journal Bearings", ASME Journal of Tribology, Vol.108, pp. $628-638$

Dowson, D. and Taylor, C. M., 1974, "Fundamental Aspects of Cavitation in Bearings", Paper I(iii), Proceedings of the 1st Leeds-Lyon symposium on Tribology, The University of Leeds, England.

Elrod, H. G., 1981, "A Cavitation Algorithm", ASME Journal of Lubrication Technology, Vol.103, pp.350-354.

Feng, N. S. and Hahn, E. J., 1987, "Effects of Gas Entrainment on Squeeze Film Damper Performance", ASME Journal of Tribology, Vol.109, pp.149154 . 
Hibner, D. H. and Bansal, P. N., 1979, "Effects of Fluid Compressibility on Viscous Damper Characteristics", Proceedings, Conference on the stability and Dynamic Response of Rotors with Squeeze Film Bearings, U.S. Army Research Office, pp.116-132.

Jacobson, B. O. and Hamrock, B. J., 1983a, "High-Speed Motion Picture Camera Experiments of Cavitation in Dynamically Loaded Journal Bearings", ASME Journal of Lubrication Technology, Vol.105, pp.446-452.

Jacobson, B. O. and Hamrock, B. J., 1983b, "Vapor Cavitation in Dynamically Loaded Journal Bearings", Proc. Inst. Mech. Eng., C206/83, pp.133140 .

Walton, II, J. F. et al, 1987, "Experimental Observation of Cavitating Squeeze-Film Dampers", ASME Journal of Tribology, Vol.109, pp.290-295.

White, D. C., 1970, Squeeze Film Journal Bearings, Ph.D dissertation, Cambridge University.

Zeidan, F. Y. and Vance, J. M., 1989, "Cavitation Leading to a Two Phase Fluid in a squeeze Film Damper Bearing", sTLE Tribology Transactions, Vol.32, pp. 100-104. 


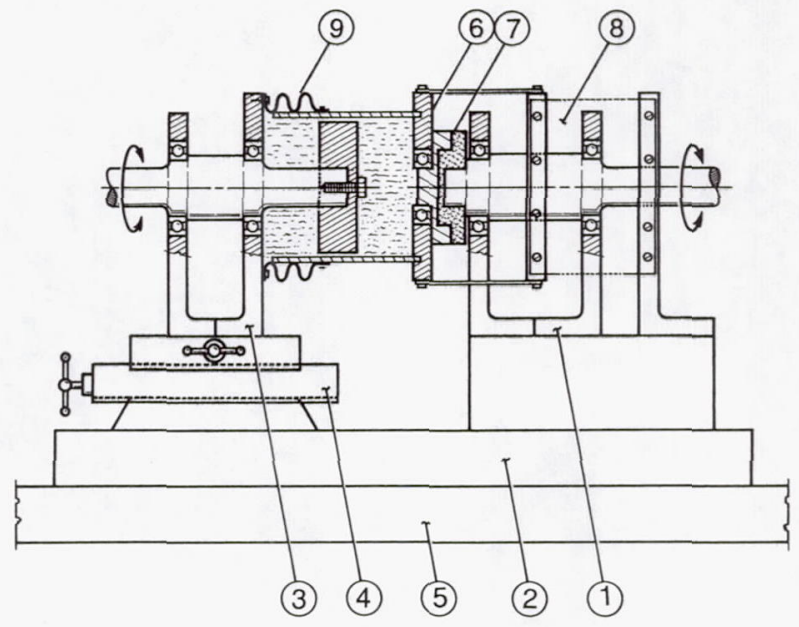

(a) SCHEMATIC.

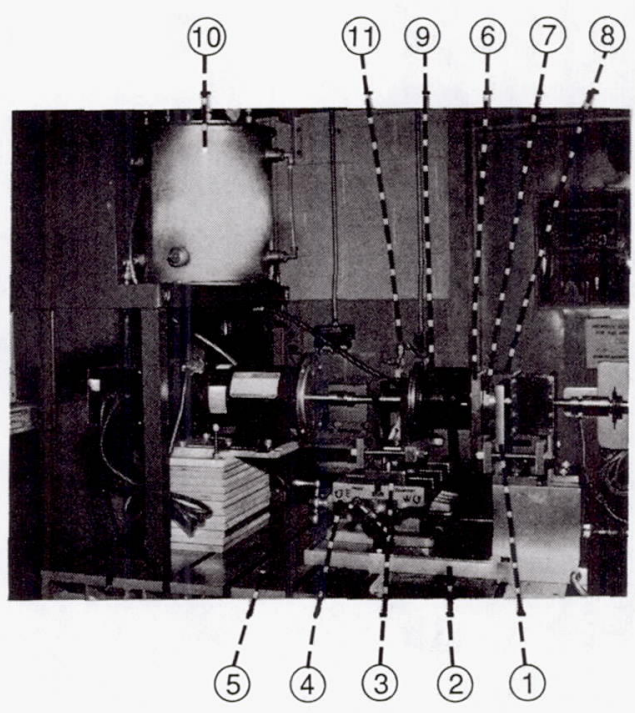

(b) PHOTOGRAPH.

FiguRE 1. - CAVITATION TEST RIG. 


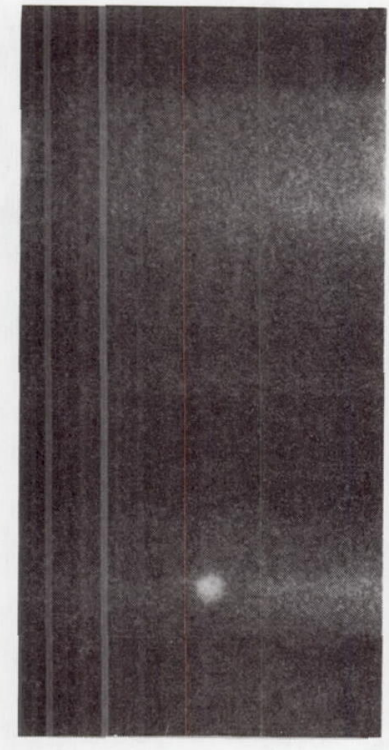

(a) CAVITATION INCEPTION.

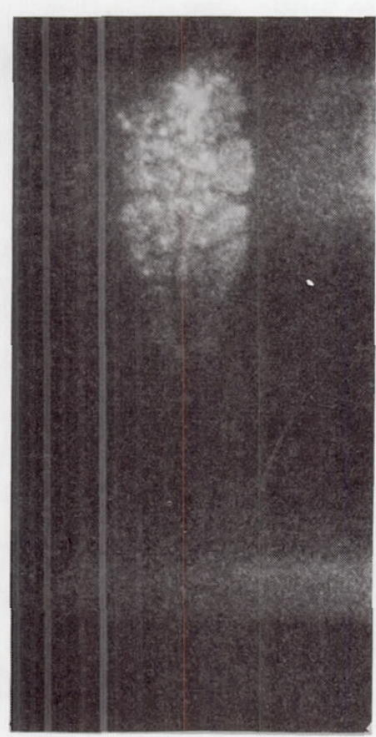

(e) $11.25 \mathrm{~ms}$.

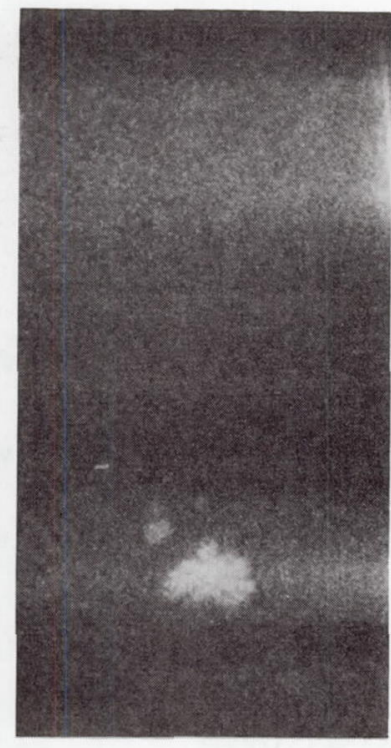

(b) $1.41 \mathrm{~ms}$.

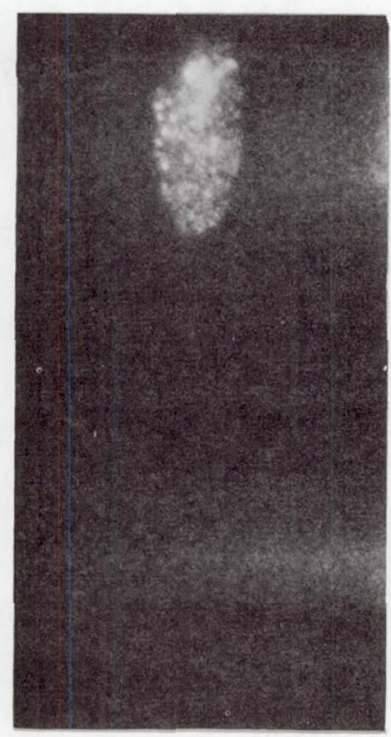

(f) $12.65 \mathrm{~ms}$.

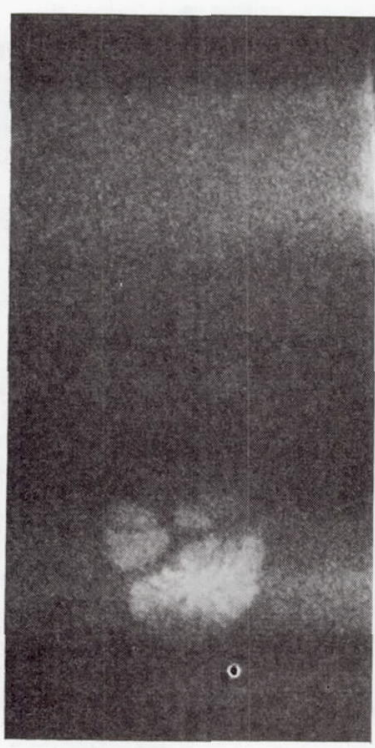

(c) $4.22 \mathrm{~ms}$.

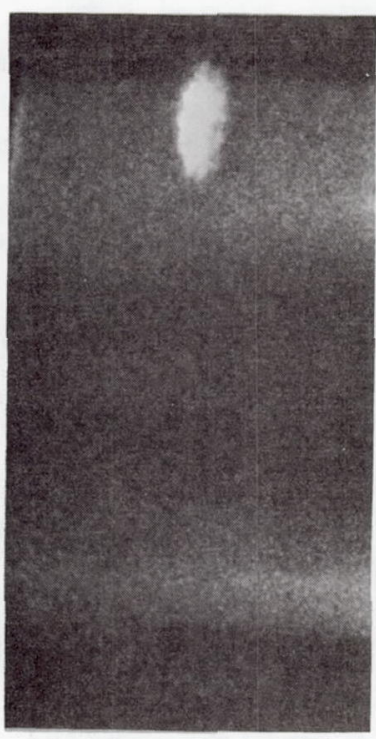

(g) $13.60 \mathrm{~ms}$

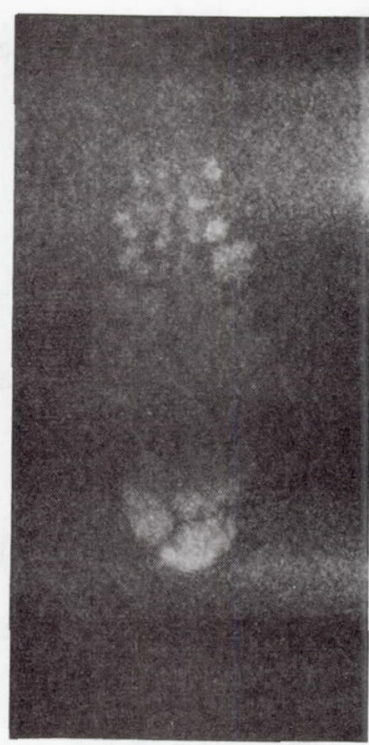

(d) $7.03 \mathrm{~ms}$.

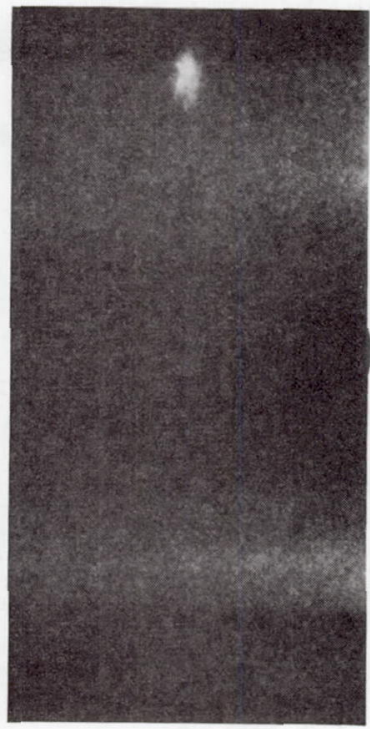

(h) CAVITATION COLLAPSE, $14.01 \mathrm{~ms}$.

FIGURE 2. - DEVELOPMENT OF A CAVITATION BUBBLE IN THE CASE OF NONCENTERED WHIRL (R/C $=84.0, L / D=0.5, \varepsilon_{s}=0.4, \varepsilon_{d}=0.55, \omega j=0.0$ RAD/s, $\omega_{b}=165.46 \mathrm{RAD} / \mathrm{s}$, CAVITATION DURATION $\left.=0.37 \mathrm{~T}\right)$. 


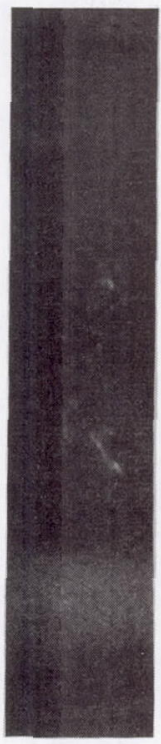

(a)

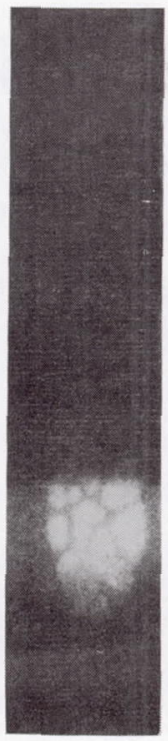

(b)

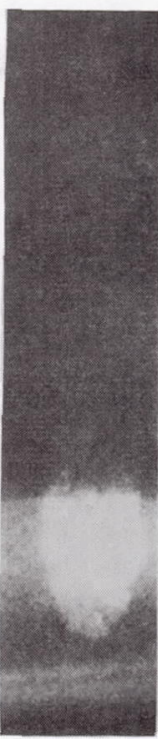

(c)

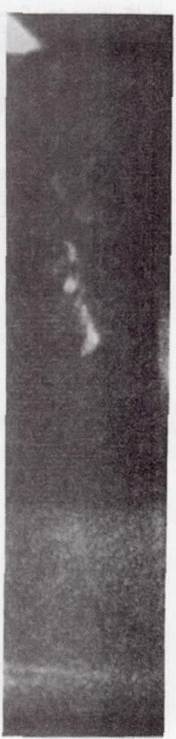

(d)

FIGURE 3. - EFFECT OF WHIRL SPEED AND AMPLITUDE ON CAVITATION $(R / C=84.0, \mathrm{~L} / \mathrm{D}=0.25$. $\left.\varepsilon_{\mathrm{S}}=0.4, \omega_{\mathrm{j}}=0.0 \mathrm{RAD} / \mathrm{s}\right)$.

(a) $\varepsilon_{\mathrm{d}}=0.5, \omega_{\mathrm{b}}=86.92 \mathrm{RAD} / \mathrm{s}$, CAVITATION DURATION $=0.083 \mathrm{~T}$.

(b) $\varepsilon_{d}=0.5, \omega_{b}=206.30 \mathrm{RAD} / \mathrm{s}$, CAVITATION DURATION $=0.33 \mathrm{~T}$

(c) $\varepsilon_{d}=0.6, \omega_{b}=90.06 \mathrm{RAD} / \mathrm{s}$, CAVITATION DURATION $=0.086 \mathrm{~T}$.

(d) $\varepsilon_{d}=0.6, \omega_{b}=147.65 \mathrm{RAD} / \mathrm{s}$, CAVITATION DURATION $=0.24 \mathrm{~T}$.

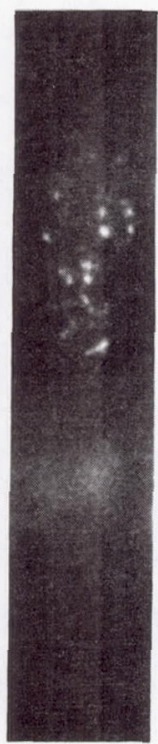

(a)

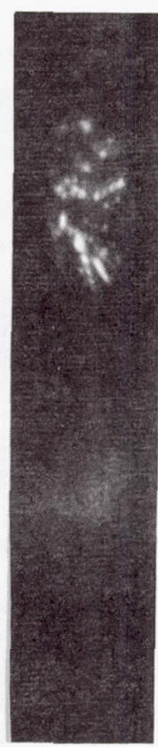

(b)

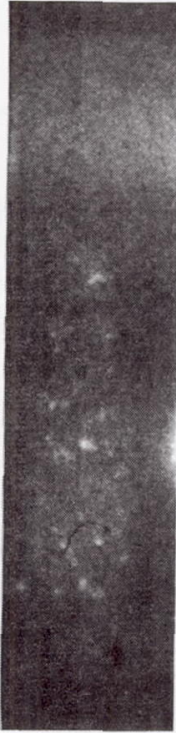

(c)

FIGURE 4. - EFFECT OF BEARING CLEARANCE ON CAVITATION (L/D $=0.25, \varepsilon_{\mathrm{s}}=0.4$, $\varepsilon_{\mathrm{d}}=0.6, \omega_{\mathrm{j}}=0.0 \mathrm{RAD} / \mathrm{s}$.

(a) $\mathrm{R} / \mathrm{C}=84.0, \omega_{\mathrm{b}}=104.72 \mathrm{RAD} / \mathrm{s}$, CAVITATION DURATION $=0.13 \mathrm{~T}$.

(b) $R / c=201.0, w_{b}=104.72 \mathrm{RAD} / \mathrm{s}$, CAVITATION DURATION $=0.23 \mathrm{~T}$.

(c) $\mathrm{R} / \mathrm{C}=201.0, \omega_{\mathrm{b}}=146.61 \mathrm{RAD} / \mathrm{s}$, CAVITATION DURATION $=0.30 \mathrm{~T}$. 


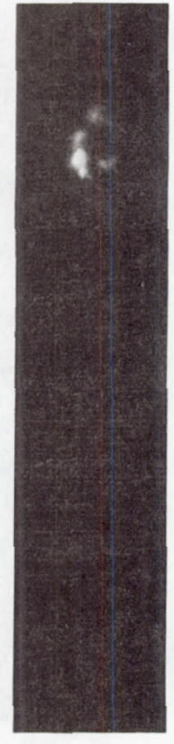

(a)

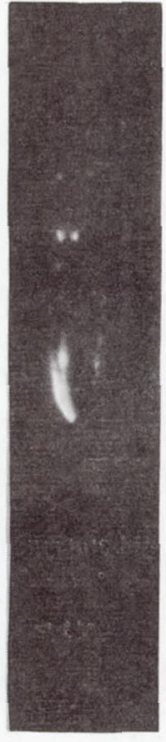

(b)

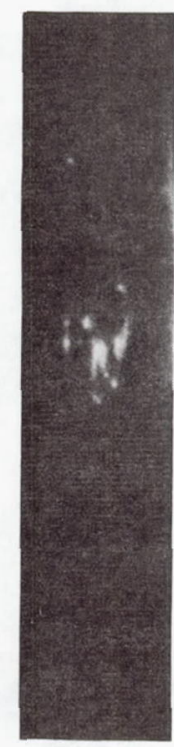

(c)

FIGURE 5. - EFFECT OF JOURNAL ROTATION ON CAVITATION (R/C $=84.0, \mathrm{~L} / \mathrm{D}=0.25$ $\varepsilon_{\mathrm{S}}=0.4, \varepsilon_{\mathrm{d}}=0.55$ ).

(a) $\omega_{b}=171.74 \mathrm{RAD} / \mathrm{s}, \omega_{j}=0.0 \mathrm{RAD} / \mathrm{s}$, CAVITATION DURATION $=0.082 \mathrm{~T}$.

(b) $\omega_{b}=167.55 \mathrm{RAD} / \mathrm{s}, \omega_{\mathrm{j}}=52.36 \mathrm{RAD} / \mathrm{s}$ ( IN THE DIRECTION OF $\omega_{\mathrm{b}}$ ),

CAVITATION DURATION $=0.24 \mathrm{~T}$.

(c) $\omega_{b}=165.46 \mathrm{RAD} / \mathrm{s}, \omega_{j}=52.36 \mathrm{RAD} / \mathrm{s}$ (OPPOSITE TO $\omega_{b}$ ), CAVITATION DURATION $=0.16 \mathrm{~T}$.

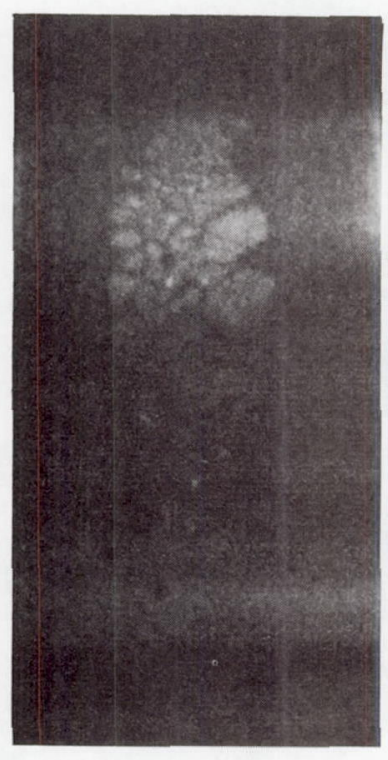

(a)

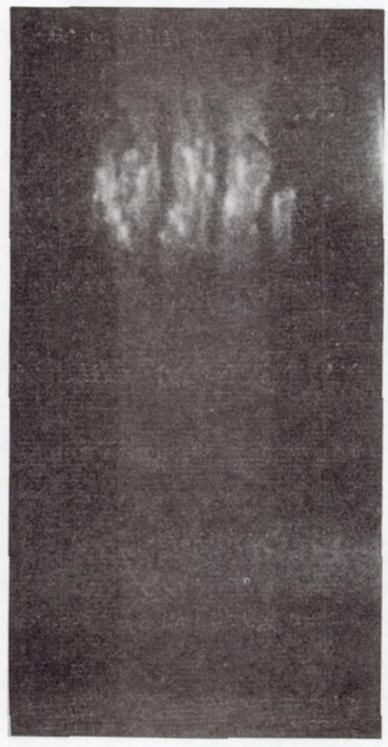

(b)

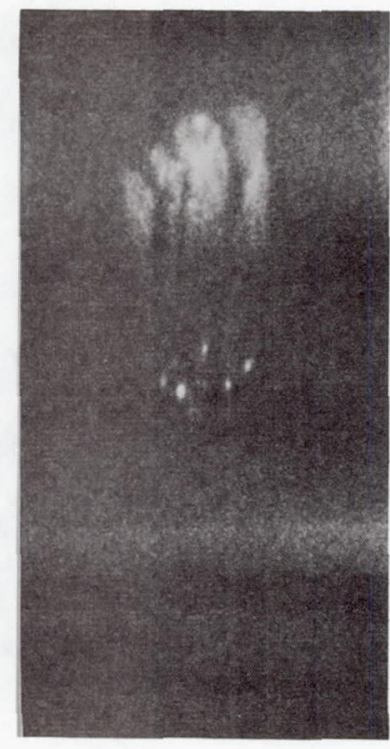

(c)

FIGURE 6. - EFFECT OF JOURNAL ROTATION ON CAVITATION (R/C $\left.=84.0, \mathrm{~L} / \mathrm{D}=0.5, \varepsilon_{\mathrm{S}}=0.4, \varepsilon_{\mathrm{d}}=0.55\right)$.

(a) $\omega_{b}=165.46 \mathrm{RAD} / \mathrm{s}, w_{j}=0.0 \mathrm{RAD} / \mathrm{s}$, CAVITATION DURATION $=0.37 \mathrm{~T}$.

(b) $\omega_{b}=157.08 \mathrm{RAD} / \mathrm{s}, \omega_{j}=52.36 \mathrm{RAD} / \mathrm{s}$ ( IN THE DIRECTION OF $\omega_{\mathrm{b}}$ ), CAVITATION DURATION $>0.44 \mathrm{~T}$.

(c) $\omega_{b}=157.08 \mathrm{RAD} / \mathrm{s}, \omega_{j}=52.36 \mathrm{RAD} / \mathrm{s}$ (OPPOSITE TO $\left.\omega_{b}\right)$. CAVITATION DURATION $=0.41 \mathrm{~T}$. 


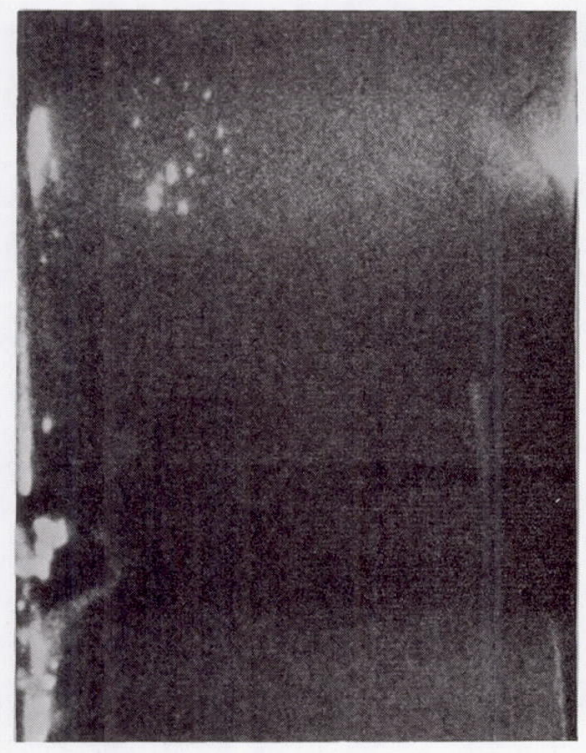

(a)

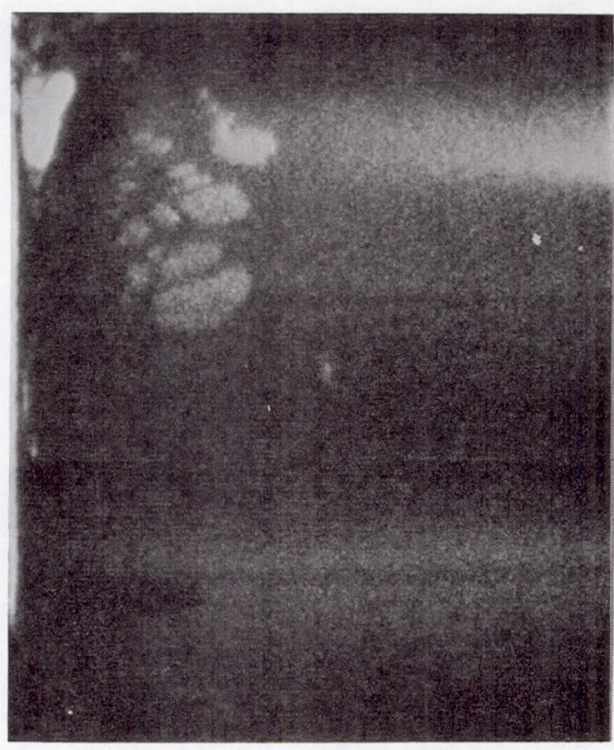

(b)

FIGURE 7. - EFFECT OF JOURNAL LENGTH ON CAVITATION (R/C $=84.0, \varepsilon_{\mathrm{s}}=0.4, \omega_{\mathrm{j}}=0.0 \mathrm{RAD} / \mathrm{s}$ ). (a) $\mathrm{L} / \mathrm{D}=1.0, \varepsilon_{\mathrm{d}}=0.56, \omega_{\mathrm{b}}=159.17 \mathrm{RAD} / \mathrm{s}$.

(b) $L / D=1.0, \varepsilon_{d}=0.6, \omega_{t}=108.91 \mathrm{RAD} / \mathrm{s}$. 


$\begin{array}{ll}\text { 1. Report No. } & \text { NASA TM-103178 } \\ & \text { AVSCOM TR 90-C-013 }\end{array}$

4. Title and Subtitle

2. Government Accession No.

3. Recipient's Catalog No.

5. Report Date

A High-Speed Photography Study of Cavitation in a Dynamically Loaded Journal Bearing

6. Performing Organization Code

7. Author(s)

D.C. Sun and D.E. Brewe

8. Performing Organization Report No.

E-5547

9. Performing Organization Name and Address

NASA Lewis Research Center

Cleveland, Ohio 44135-3191

and

Propulsion Directorate

U.S. Army Aviation Research and Technology Activity-AVSCOM

Cleveland, Ohio 44135-3127

12. Sponsoring Agency Name and Address

National Aeronautics and Space Administration

Washington, D.C. 20546-0001

and

U.S. Army Aviation Systems Command

St. Louis, Mo. 63120-1798

10. Work Unit No.

505-63-64

1L161102AH45

11. Contract or Grant No.

13. Type of Report and Period Covered

Technical Memorandum

14. Sponsoring Agency Code

15. Supplementary Notes

Prepared for the Joint Tribology Conference cosponsored by ASME and STLE, Toronto, Canada, October 7-10, 1990. D.C. Sun, Department of Mechanical and Industrial Engineering, Thomas J. Watson School of Engineering, Applied Science, and Technology, State University of New York at Binghamton, Binghamton, New York 13902-6000 and Summer Faculty Fellow at NASA Lewis Research Center. D.E. Brewe, Propulsion Directorate, U.S. Army Aviation Research and Technology Activity-AVSCOM.

16. Abstract

The earlier study made by Jacobson and Hamrock on the cavitation of liquid lubricant films in a dynamically loaded journal bearing was repeated with a quartz sleeve, which was more rigid than the Polymethylmethacrylate (PMMA) sleeve used previously. Various improvements of the test rig were made concomitantly so that the experimental errors could be better controlled and assessed. This paper describes the updated high-speed photography experiment and its results.

17. Key Words (Suggested by Author(s))

Cavitation; Journal bearing; Fluid-films; Bearings; Dynamic loads; Hydrodynamics; Gaseous cavitation; Vaporous cavitation; High-speed photography
18. Distribution Statement

Unclassified-Unlimited

Subject Category 37

19. Security Classif. (of this report)

Unclassified

20. Security Classif. (of this page)

Unclassified

21. No. of pages

22. Price $^{*}$ 